\title{
Quantifying the spatio-temporal patterns of settlement growth in a metropolitan region of Ghana
}

\author{
Ransford A. Acheampong • Felix S. K. Agyemang • \\ Mohammed Abdul-Fatawu
}

Published online: 2 May 2016

(C) The Author(s) 2016. This article is published with open access at Springerlink.com

\begin{abstract}
Retrospective understanding of the magnitude and pace of urban expansion is necessary for effective growth management in metropolitan regions. The objective of this paper is to quantify the spatialtemporal patterns of urban expansion in the Greater Kumasi Sub-Region (GKSR) - a functional region comprising eight administrative districts in Ghana, West Africa. The analysis is based on Landsat remote sensing images from 1986, 2001 and 2014 which were classified using supervised maximum likelihood algorithm in ERDAS IMAGINE. We computed three complementary growth indexes namely; Average Annual Urban Expansion Rate, Urban Expansion Intensity Index (UEII) and Urban Expansion Differentiation Index to estimate the amount and intensity of expansion over the 28-year period. Overall, urban expansion in the GKSR has been occurring at an average annual rate of $5.6 \%$. Consequently, the subregion's built-up land increased by $313 \mathrm{~km}^{2}$ from $88 \mathrm{~km}^{2}$ in 1986 to $400 \mathrm{~km}^{2}$ in 2014 . The analysis further show that about $72 \%$ of the total built-up land
\end{abstract}

R. A. Acheampong $(\bowtie) \cdot$ F. S. K. Agyemang

Lab of Interdisciplinary Spatial Analysis, Department of Land Economy, University of Cambridge, 19 Silver

Street, Cambridge CB3 9EP, UK

e-mail: raa49@cam.ac.uk

M. Abdul-Fatawu

Faculty of Geo-Information Science and Earth

Observation, University of Twente, 7500 AE Enschede,

The Netherlands increase occurred in the last 13 years alone, with UEII value of 0.605 indicating a moderate intensity of urban expansion. Moreover, the metropolitan-core of the sub-region, being the focal point of urban development and the historical origins of expansion, accounted for more than half of the total built-up land increase over the 28 -year period. Over the last decade and half however, urban expansion has spilled into the neighbouring peripheral districts, with the highest intensity and fastest rate of expansion occurring in districts located north and north east of the subregional core. We recommend a comprehensive regional growth management strategy grounded in effective strategic partnerships among the respective administrative districts to curb unsustainable urban expansion.

Keywords Urbanization - Urban expansion - Spatiotemporal change - Landsat · GIS · Greater-Kumasi · Ghana

\section{Introduction}

Rapid and unfettered urban expansion constitutes one the visible manifestations of the on-going urbanization process in cities of the Global South. The growth of urban areas in these regions have been fuelled by the demographic processes of natural population growth and rural-urban migration as well as the 
reclassification of previously rural settlements into urban centres (Potts 2012; UN-Habitat 2010).

In broad terms, urban expansions could be categorised into the three interrelated processes of infilling, expanding, and outlying (Wilson et al. 2003). Infilling results in relatively compact and consolidated physical development. In most cities in developing countries however, rapid peri-urbanization, characterised by unconsolidated lateral physical expansion and sprawl, has resulted in existing built-up areas engulfing smaller towns on their peripheries (Webster 2002; Kombe 2005; Doan and Oduro 2012). As contemporary form of urbanization, the uncontrolled expansion of urban centres into their peripheries has been driven by the need to accommodate rapid population growth and to meet the attendant space demands of various socio-economic activities often at the expense of Greenfield land (Acheampong and Anokye 2013; Appiah et al. 2014; Owusu-Ansah and O'Connor 2006).

Although there is emerging evidence that suggests that urbanization particularly, in Sub-Saharan Africa has been occuring very slowly or even stagnated (Potts 2012), there is a general consensus that its accumulated impacts over the years, poses various challenges to urban growth management and sustainable development. The emerging challenges of climate change, environmental degradation and resource depletion resulting from decades of rapid urbanization (Watson 2009), pose serious threats to public health, the continuous supply of essential eco-system services and food security (Eigenbrod et al. 2011; Baloye and Palamuleni 2015).

Gaining a retrospective understanding of the spatiotemporal urban land-use dynamics and the underlying driving-forces is crucial to managing growth to avert unstainable urban expansion and the associated negative impacts. Adequate and reliable data through conventional surveying and mapping techniques have however, been either unavailable, limited in scope, expensive or time consuming to acquire for accurate analysis of historical urban expansion at different spatial scales (Jat et al. 2008).

In recent years, land use changes in many countries have been monitored and predicted at the national, regional and city scales using satellite remote sensing imagery (e.g. Wakode et al. 2014; Xu et al. 2007). Among the commonly used satellite sensors is the Thematic Mapper (TM) on board the Landsat series satellite platforms, providing quality land cover data at spatial and temporal resolution required for land-use change studies. A number of challenges exist in using satellite imagery to detect land use change, including the many combinations of materials present and the variations in size or shape of urban features that can lead to different 'mixtures' within pixels (Schneider 2012; Xian and Crane 2005). Notwithstanding, combined with Geographical Information Systems (GIS), Landsat satellites have provided multi-spectral and multi-temporal data that have been used extensively for land cover mapping, environmental modelling and land use modelling (e.g. Schneider 2012; Masek et al. 2000; Wakode et al. 2014).

In this paper, we use Landsat remote sensing imagery from 1986, 2001 and 2014, GIS analytical techniques and spatial metrics to quantify the spatiotemporal patterns of urban expansion within the Greater Kumasi Sub-Region (GKSR) in Ghana. The GKSR is a newly designated, rapidly urbanizing metropolitan region in Ghana, comprising the Kumasi metropolis, the country's second largest metropolitan area, and seven peripheral districts. In recent years, a number of empirical studies have sought to understand urban expansion trends in the sub-region. Using OpenStreetMap and Google Earth, Oduro et al. (2014), analyzed drivers of urban growth in the subregion. Cobbinah and Amoako (2012), estimated historical land-use distribution in the Kumasi metropolis - the historical core of the sub-region between 1995 and 2010. Other studies have addressed urban expansion and its implications in selected peri-urban towns in the sub-region (e.g. Acheampong and Anokye 2013; Amoateng et al. 2013; Appiah et al. 2014).

While some of these previous studies have provided descriptive analysis of the reasons driving rapid periurban development in the sub-region based on survey data (e.g. Acheampong and Anokye 2013; OwusuAnsah and O'Connor 2006), others have relied on data from government departments obtained from existing land-use plans and/or through conventional mapping techniques such as field-updates (e.g. Amoateng et al. 2013; Cobbinah and Amoako 2012). Data from land use plans, for example, allows to estimate detailed land-use distributions in areas covered by planning schemes. However, relying on this alone could underestimate the quantum of built-up land in the study area since in Ghana, for example, land use plans can provide data only for areas covered by planning 
schemes. Moreover, owning to the lack of frequent updates of these land use plans by the physical planning departments, data derived from them is often unreliable and fraught with accuracy problems.

The current paper builds on the empirical insights accrued over the years from these initial research. Our approach and contribution, however differs considerably from these initial works in terms of the spatial extent of the analysis, temporal scope, data sources and methodology. This study, constitutes the first attempt to apply Landsat satellite data and spatial metrics to quantify historical urban expansion at the macro (i.e. sub-regional) and micro (i.e. district-level) scales over a period of 28 years.

The remainder of the paper is organized as follows: In the section that follows, we discuss the typology and manifestations of urban expansion to set the framework for the study. This is followed with a discussion of research methodology focusing on data acquisition, Landsat satellite image classification and accuracy assessment processes as well as the spatial metrics applied in computing urban expansion indexes. The results are presented in the penultimate section followed with a discussion of the results and policy implications.

\section{Understanding and estimating settlement expansion}

Urbanization, in broad terms, is a process by which settlements increase in population, physical size and economic activities over time. Agglomeration theory posits that the concentration of population and economic activities underpin the urbanization process, and has historically been responsible for the emergence and growth of cities and large metropolitanregions (Jacobs 1969; Henderson 2002). Urbanization generates external economies of scale, which not only enhance productivity and growth but reinforces the potential of existing cities as major attraction points for additional population and activities (Duranton and Puga 2004; Henderson 2002).

Aside demographic change, urbanization shapes the form and structure of settlements through the physical expansion of existing built-up areas into Greenfield land or surrounding rural settlements (UNHabitat 2010). Within the context of this study, urban expansion refers the physical process characterised by an increase in the quantum of built-up land of a spatial unit through the combination of horizontal and vertical development at varying densities. The expansion of urban areas take place in substantially different forms in different contexts which makes it difficult to propose any single theoretical model, either descriptive or analytical to explain the phenomenon. Although classical models of urban spatial structure, grounded in urban micro-economics, offer useful theoretical insights into how cities grow and the general emergent patterns of land uses (see e.g. Alonso 1964; Burgess 1925), these models seem constrained to their specific cities of origin. Moreover, they address a broad range of urban growth phenomenon and are unable to account for the different manifestations of physical urban expansion.

In the absence of a general theoretical model, research has focused on understanding the processes of urban change and forms of urban expansion. Suburbanization, as a process of urban change is a common phenomenon in cities of the developed countries. In broad terms, suburbanization is associated with lowdensity, often fragmented and sprawling physical development on Greenfield land immediately surrounding existing built-up land of a city (Champion 2001; Pacione 2009). In cities of the Global South, peri-urban development typifies the unprecedented urbanization marked at the beginning of the 21 st century (UN-Habitat 2010). Consensus on a precise definition of the 'periurban' sometimes referred to as 'urban fridge' is lacking in the literature. Two main definitional approaches have been adopted in conceptualizing peri-urban areas. The first approach conceptualizes peri-urban areas in terms of discrete spatial limits. Based on empirical observation, leading exponents of this approach suggest a distance of about $30-50 \mathrm{~km}$, beyond the existing builtup land of major cities, as a reasonable generalization of the extent of the peri-urban zone (see e.g. McGregor and Simon 2012; Webster 2002). Simon et al. (2004) estimates that the peri-urban zone of Kumasi, for example, stretches some 20 to 40 kilometres radius around the city's main built-up area.

The second definitional approach for peri-urban areas adopts an integrated and functional view by considering the urban-rural continuum. Based on this, the urbanperiphery is conceptualized as a transition zone between fully urbanized land in cities, and areas in predominantly agricultural use (McGregor et al. 2011; Webster 2002). As transition zones between the urban and rural, peri- 
urban areas are characterised by mixed land uses and indeterminate inner and outer boundaries, and are often split between a number of administrative areas (McGregor et al. 2011; Webster 2002). In Ghana for example, the lack of effective co-ordination among local governments coupled with a generally weak development control system (Acheampong and Ibrahim 2015; Owusu-Ansah and O'Connor 2006) presents major challenges for effective land use planning and development management in peri-urban areas.

Different forms of physical expansion emerge through suburbanization and peri-urbanization. In any given city or metropolitan region, urban expansion can be compact through the infill of existing open spaces in already built-up areas and or redevelopment of built-up areas at higher densities (Angel et al. 2005; Wilson et al. 2003). Furthermore, urban expansion may occur either as contiguous extensions to existing built-up areas or spontaneous leapfrog development away from main built-up land, leaving swaths of undeveloped land that separate the new development from existing built-up areas (Torrens and Alberti 2000). This form of expansion normally occurs in linear direction along major road networks (i.e. ribbon development) and or in radial direction around an already established built-up area (Sudhira et al. 2004).

Drawing on the processes and manifestations of urban expansion, several studies have attempted to identify and quantify the pace, amount and intensity of urban expansion using spatial metrics and GIS analytical techniques. Among the commonly used metrics are Landscape Expansion Index (LEI) (Liu, et al. (2010), Urban Expansion Intensity Index (UEII) (HU et al. 2007; Li et al. 2010) and Urban Expansion Differentiation Index (UEDI) (Lu et al. 2014). We adopt a similar approach in this paper to estimate the spatio-temporal patterns of urban expansion in the GKSR. A detailed description of our approach are discussed in the section that follows.

\section{Methods}

Study area

The GKSR is located in the Ashanti Region, one of the ten administrative regions in Ghana (Fig. 1). The subregion was designated in 2010 by the Town and Country Planning Department as a functional planning area for purposes of strategic regional planning and sustainable growth management. The first spatial development plan for the sub-region, 'The Comprehensive Urban Development Plan for Greater Kumasi' was adopted for implementation in 2013. The sub-region stretches between latitude $6.35^{\circ}-$ $6.40^{\circ} \mathrm{N}$ and longitude $1.30^{\circ}-1.35^{\circ} \mathrm{W}$, with an elevation ranging between 250 and $300 \mathrm{~m}$ above sea level. It covers a contiguous area of approximately $2850 \mathrm{~km}^{2}$ of urban, peri-urban and rural land.

The sub-region comprises one metropolitan area (i.e. KMA) and seven immediate surrounding districts namely; Afigya-Kwabre District, Kwabre East District, Ejisu-Juaben Municipality, Bosomtwe District, Atwima-Kwanwoma District and Atwima-Nwabiagya District (Fig. 1). As the functional core of the subregion, KMA covers a total land area of about $250 \mathrm{~km}^{2}$, representing about $9 \%$ of GKSR's total land area. At the centre of the metropolis is located the sub-region's Central Business District (CBD), surrounded by over 50 settlements within its inner and outer-suburban zones.

According to the most recent census data available, the GKSR has an estimated population of 2,764,091, representing about $58 \%$ of the total population of the Ashanti Region and $11 \%$ of Ghana's population (Table 1). The $\mathrm{KMA}^{1}$ is the most populous area within the sub-region accounting for $74 \%$ (i.e. over two million) of its total population.

Overall, the sub-region's population, based on the intercensal estimates for 2000 and 2010, is estimated to be growing at an annual rate of $4.62 \%$ compared to the average annual growth rates of 2.84 and $2.69 \%$ for the Ashanti Region and Ghana respectively. Among the rapidly growing districts within the sub-region are the Kumasi metropolis, Afigya Kwabre and Bosomtwe districts with annual population growth rates of 5.69, 4.30 and $3.47 \%$ respectively.

Landsat satellite data acquisition and preparation

For this study, we used raster spatial data comprising three Landsat satellite images (row 55, path 194) for

\footnotetext{
1 The population of the Kumasi Metropolis includes that of the Asokore-Mampong Municipality. Until after the 2010 population census, when the latter was carved out of the former as a separate administrative unit, the two districts together constituted the Kumasi Metropolitan Area.
} 


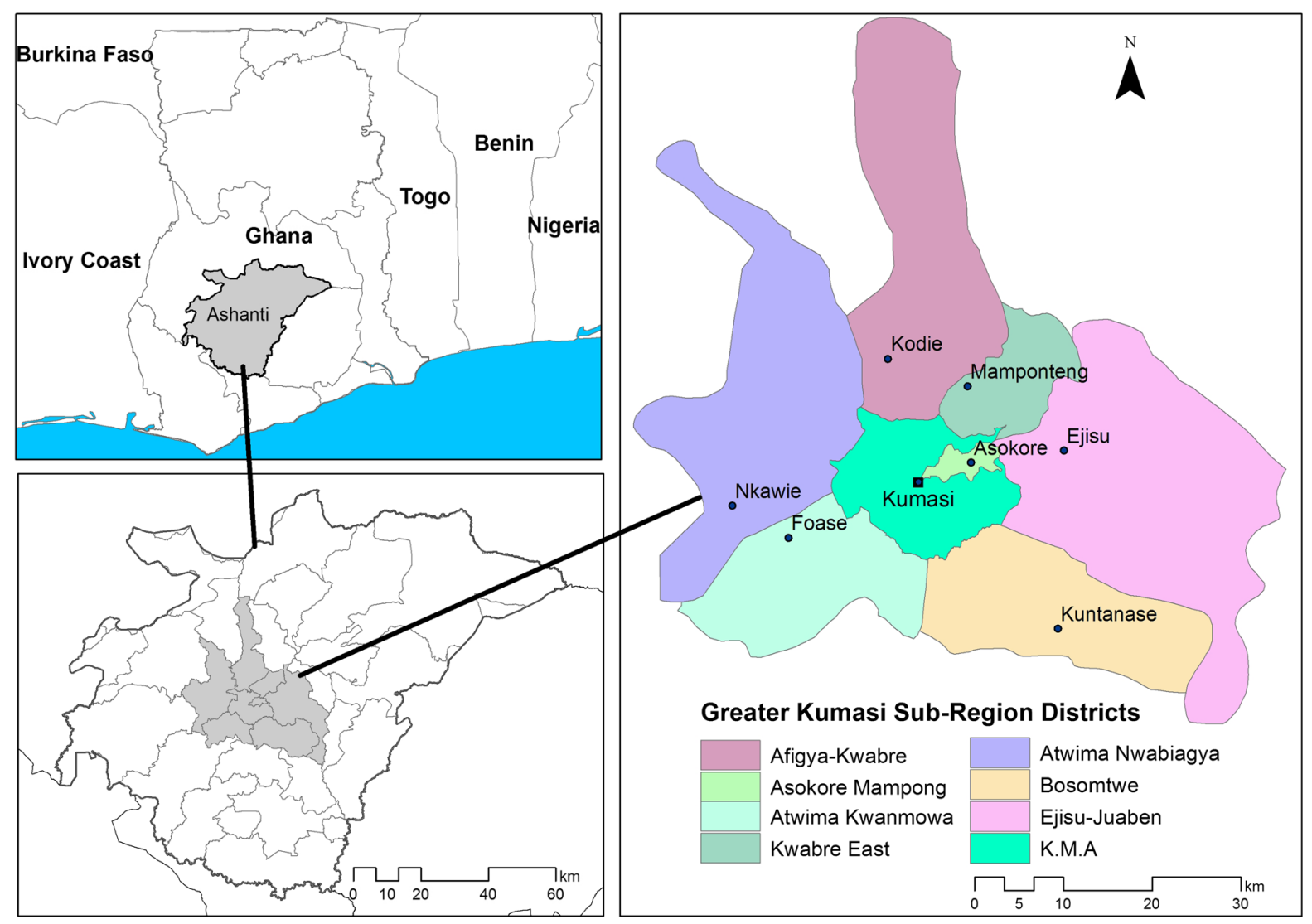

Fig. 1 Location of study area

Table 1 Population size and growth rates within the GKSR (1984-2010) Source: Based on 1984, 2000 and 2010 Population and Housing Census, Ghana Statistical Service

\begin{tabular}{|c|c|c|c|c|c|}
\hline \multirow[t]{2}{*}{ Districts } & \multicolumn{2}{|c|}{ Population size } & \multicolumn{3}{|c|}{ Annual population growth rate $(\%)$} \\
\hline & 1984 & 2000 & 2010 & 1984-2000 & $2000-2010$ \\
\hline Atwima Nwabiagya & 56,352 & 127,809 & 149,025 & 5.25 & 1.55 \\
\hline Ejisu-Juaben & 78,783 & 124,176 & 143,762 & 2.88 & 1.48 \\
\hline Kwabre East & 42,044 & 101,100 & 115,556 & 5.64 & 1.35 \\
\hline Atwima Kwanmowa & 44,437 & 79,240 & 90,634 & 3.68 & 1.35 \\
\hline Afigya-Kwabre & 39,971 & 89,358 & 136,140 & 5.16 & 4.30 \\
\hline K.M.A and Asokore-Mampong & 487,504 & $1,170,270$ & 2,035064 & 5.63 & 5.69 \\
\hline Bosomtwe & 41,283 & 66,788 & 93,910 & 3.05 & 3.47 \\
\hline Greater Kumasi Sub-Region & 734,022 & $1,758,741$ & 2,764091 & 5.13 & 4.62 \\
\hline Ashanti Region & $2,090,100$ & $3,612,950$ & 4,780380 & 3.48 & 2.84 \\
\hline Ghana & $12,296,081$ & $18,912,079$ & $24,658,823$ & 2.73 & 2.69 \\
\hline
\end{tabular}

1986 (TM), 2001 (ETM+) and 2014 (OLI/TIRS) downloaded from the United States Geological Survey website as standard products. As with most city-region scale urban expansion studies (see e.g. Herold et al. 2002; Wakode et al. 2014), the images had a spatial resolution of $30 \mathrm{~m}$. 
The satellite images were first geometrically referenced to the WGS 1984 UTM Zone $30 \mathrm{~N}$ coordinate system. The 2001 image had $20 \%$ cloud cover while the 1986 and 2014 images had cloud cover $<10 \%$. The cloud cover on the 2001 image was therefore high and needed to be corrected in order not to affect the accuracy results of the image classification and interpretation. In order to overcome this challenge, Google earth images covering the same period (i.e. 2001) were downloaded and compared with the corresponding Landsat image. Using this approach, the specific land cover types within the areas covered by clouds were identified and recorded.

However, even within Google Earth, some areas still had thick cloud cover which made it difficult to identify the specific land cover there with a high degree of certainty. For these areas, ground-truthing was carried out in order to ascertain the land cover classes to which they belonged. Combining the Google Earth verification and ground-truthing techniques, we found that the significant part of the 2001 Landsat image covered by clouds, were the non-built-up areas (i.e. natural vegetation) with only small portion $(<5 \%)$ covering some built-up areas. The portions of the 2001 image covered by clouds and which were identified to be natural vegetation were selected as areas of interest to be recoded into the actual land cover classes as non-builtup. Similarly, the portions identified as built-up were recoded into the land cover classes as built-up land.

Landsat satellite image classification and accuracy assessment

Using the supervised maximum likelihood classification algorithm in ERDAS IMAGINE, we classified the Landsat images into three discrete land cover classes identified as 'Built-up', 'Non-built-up' and Water. Due to the additional and differentiated bands of Landsat OLI/TIRS data, the combinations used to create the natural colour composites differ from the previous series. For example, bands 7, 5 and 3 are used to create the natural colour composite of Landsat 7 ETM+ images. In this study, we used bands 7, 6 and 4 of the Landsat OLI/TIRS image since this combination provides a natural-like rendition while also penetrating atmospheric particles, smoke and haze. Following conventional classification typologies, the built-up cover class comprised the physical aspect of the urban fabric including roads, all buildings used for residential, commercial and industrial purposes and their immediate surroundings, and other built-up lands. The non-built-up category included farmlands, grasslands, bare-land, forests and other vegetation.

Training samples for each of the three classes were selected by visual interpretation of (a) true colour composites of the Landsat imagery (b) very high resolution (VHR) images from Google Earth and (c) ground truthing/participatory mapping. Accuracy assessment of the classified land cover maps was done with the aid of 235 randomly selected validation points. The actual land cover of each validation point was identified for the years in question as follows: (1) a visual interpretation of the true colour composite for the 1986 image (2) for 2001 image: land use map of 2000 on a scale of 1: 50000 combined with visual interpretation of VHR Google Earth image and (3) visual interpretation of VHR Google Earth image of 2014. The accuracy assessment yielded overall classification accuracies of $92.0 \%, 88.20$ and $92.0 \%$, and a corresponding overall kappa statistics of $0.80,0.76$ and 0.80 for the 1986, 2001 and 2014 images respectively. Compared with the accuracy results of urban growth studies, our accuracy assessment results was considered very good to allow for accurate analysis of the rate of urban expansion in the GKSR.

Quantifying settlement growth and expansion: spatial metrics

In using the classified images to detect and quantify urban expansion in the GKSR, we adopted three complementary spatial metrics/indexes. The first metric applied is the Average Annual Urban Expansion Rate (AUER). AUER is a historical metric that computes the mean annual rate of expansion of built-up land of a spatial unit between two periods - the base year and the ending year. As depicted in Eq. 1, AUER is a modification of the compound growth rate formula used, for example, in estimating mean annual population growth rate. The result of the index, is therefore a representational figure which estimates the rate at which the quantum of built-up land of a spatial unit is changing.

$A U E R_{i}=\left[\left(\frac{U L A_{i}^{t_{2}}}{U L A_{i}^{t_{1}}}\right)^{\frac{1}{t_{2}-t_{1}}}-1\right] \times 100$

where $A U E R_{i}$ is Annual Urban Expansion Rate; $U L A_{i}^{t_{2}}$ and $U L A_{i}^{t_{1}}$ are the area of built-up land at time $t_{2}$ and $t_{1}$ 
respectively. The AUER is not affected by the size of the spatial unit and does not have upper and lower limits.

In addition, we computed Urban Expansion Intensity Index (UEII). UEII, as shown in Eq. 2, computes the average annual proportion of newly increased built-up land of a spatial unit, standardized by the total area of that spatial unit (HU et al. 2007; Li et al. 2010).

$U E I I_{i}=\frac{U L A_{i}^{t_{2}}-U L A_{i}^{t_{1}}}{T L A_{i} \times \Delta t} \times 100$

where $U E I I_{i}$ is Urban Expansion Intensity Index of unit $i$; $U L A_{i}^{t_{2}}$ and $U L A_{i}^{t_{1}}$ are the area of built-up land at time $t_{2}$ and $t_{1}$ respectively; $T L A_{i}$ is the total land area within the study area $i$ and $\Delta t$ is the study time period (i.e. $t_{2}-t_{1}$ ). The UEII describes the degree of differentiation of urban expansion in different directions and denotes the growth of the built-up areas of a spatial unit as a percentage of the total area of land in the study period (HU et al. 2007). The division standard for interpreting UEII values is as follows: values $>1.92$ is "high-speed"; values between 1.05 and 1.92 is "fast"; values between 0.59 and 1.05 is "mediumspeed"; values between 0.28 and 0.59 is "low-speed"; and values between 0 and 0.28 is considered "slow" (see e.g. Ren et al. 2013).

The third metric used is the Urban Expansion Differentiation Index (UEDI). UEDI refers to the ratio of the urban expansion rate of a spatial unit to the urban expansion rate of the study area. Unlike the UEII, UEDI quantifies the urban land expansion disparity between different spatial units, thereby making those units comparable. This metric is useful in evaluating regional urban land expansion differentiation and identifying urban expansion hotspots ( $\mathrm{Lu}$ et al. 2014). The UEDI is shown in Eq. 3:

$U E D I_{i}=\frac{\left|U L A_{i}^{t_{2}}-U L A_{i}^{t^{1}}\right| \times U L A^{t_{1}}}{\left|U L A_{i}^{t_{2}}-U L A_{i}^{t^{1}}\right| \times U L A_{i}^{t^{1}}}$

where $U E D I_{i}$ is the urban expansion differentiation index of unit $i ; U L A_{i}^{t_{2}}$ and $U L A_{i}^{t^{1}}$ indicate the area of built-up land of unit $i$ at time $t_{2}$ and $t_{1}$ respectively; and $U L A^{t_{2}}$ and $U L A^{t^{1}}$ indicate the total area of urban land in the study area at time $t_{2}$ and $t_{1}$ respectively. Unlike UEII, UEDI, does not follow a standard categorization range. It compares urban expansion of a constituent spatial unit to the overall study area. Mathematically, the urban differentiation index of the overall study area-the sub-region in the context of this study-is always equal to 1 , and serves as the yardstick for identifying the development hotspots in the subregion. Generally, there could be three possible categories of UEDI: (1) when the constituent spatial unit (i.e. district) has a differentiation index $>1$ in which case, the district is categorized as "fast" growing area in relation to the sub-region; (2) where the differentiation index of the district is $<1$ in which case the district is categorized as "slow" growing area in relation to the sub-region and (3) when the differentiating index of the district is equal to 1 in which case the district is categorized as "moderate" growing area in relation to the sub-region.

The urban expansion quantification using the classified images and the metrics discussed above, was carried out in ArcGIS 10.1 software. The results of the analysis are presented at two spatial scales. At the macro scale, the various urban expansion indexes are interpreted for the GKSR as a whole. This is followed by a micro-level analysis where we interpret the same indexes for the individual administrative districts in the sub-region.

\section{Results}

Urban expansion dynamics in GKSR: macro level analysis

Over the last approximately three decades, urban expansion in the GKSR has been massive and very rapid. Increasing annually at an average rate of $5.6 \%$, the total built-up land of the sub-region more than quadrupled from an estimated $88 \mathrm{~km}^{2}$ in 1986 to $400 \mathrm{~km}^{2}$ in 2014 . Thus, whereas in 1986 only $3.1 \%$ of the total land area of the GKSR was built-up, this increased to $14 \%$ in 2014 (Fig. 2).

Breaking the analysis down into the first 15-year period (i.e. 1986 to 2001) and the last 13-year period (i.e. 2001-2014), we found that the pace of urban expansion in the sub-region has been occurring at an increasing rate within the latter period. This is evidenced by the fact that the Annual Urban Expansion Rate increased from $4.8 \%$ between 1986 and 2001 to $6.5 \%$ between 2001 and 2014. Indeed, the extent of urban expansion over the two broad time- 


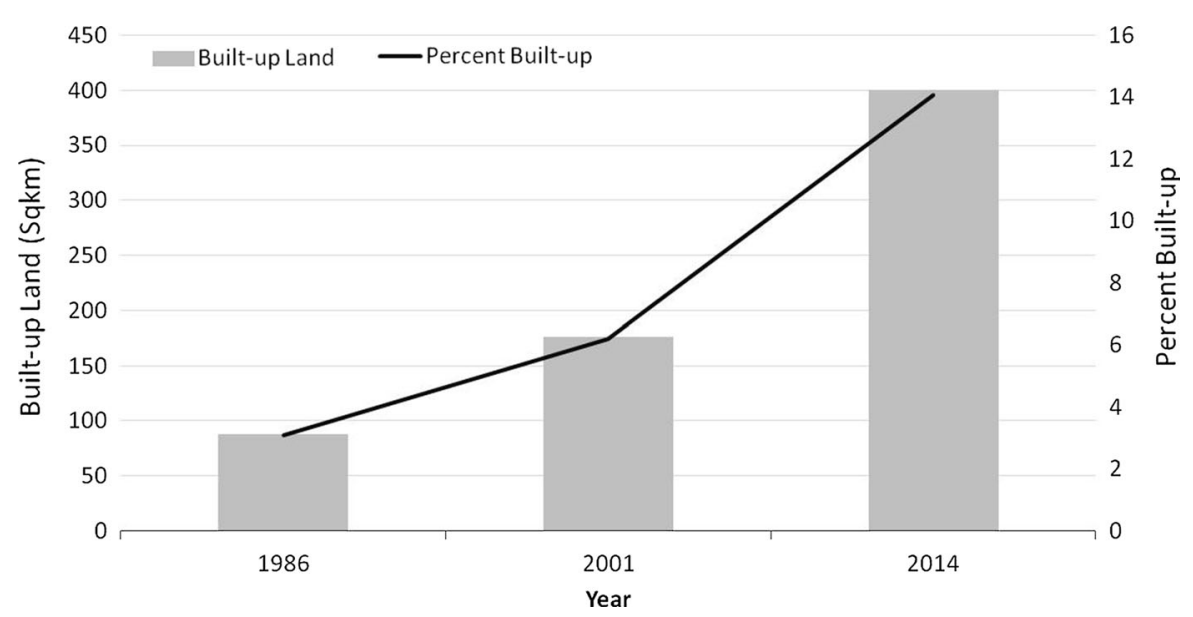

Fig. 2 Change in built-up land and percentage share of built-up land to total land area in GKSR

periods is confirmed by the broad land cover classification maps depicted in Fig. 3. In absolute terms, the total built-up land in the sub-region increased by approximately $313 \mathrm{~km}^{2}$ over the 28 -year period. Out of this, approximately $72 \%\left(224 \mathrm{~km}^{2}\right)$ occurred during the last 13 years compared with $28 \%$ $\left(89 \mathrm{~km}^{2}\right)$ during the first 15 years. Thus, the quantum of urban expansion that occurred over the last 13-year period was about two and half times that of the first 15 years.
Moreover, the Urban Expansion Intensity Index (UEII), which standardises the Annual Urban Expansion Rate by the total land area of the sub-region, reveals a similar spatio-temporal pattern of built-up land cover change. With a UEII value of 0.207 , the intensity of urban expansion was slow during the first 15 years. However, the sub-regions' UEII increased almost three times to 0.605 during the last 13 years, indicating a moderate intensity of urban expansion over the period. The available census information

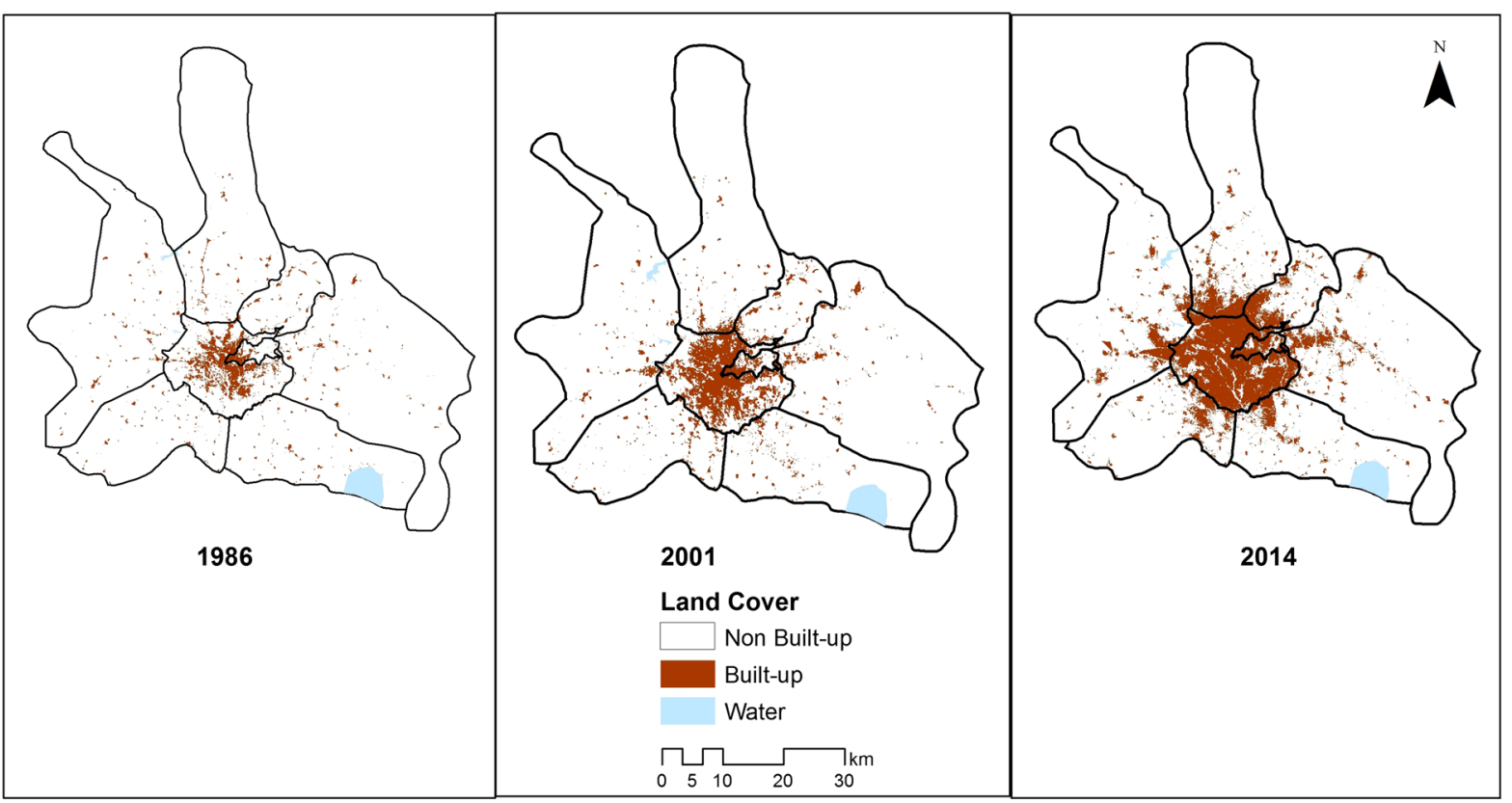

Fig. 3 Broad land cover classification, 1986, 2001 and 2014 
indicates that over the past two and a half decades, the sub-region's population has also been growing rapidly at an annual rate of $5.1 \%$. The rapid increase in builtup land has therefore been occurring in tandem with rapid population growth in the sub-region.

Urban expansion dynamics in GKSR: micro level analysis

\section{Districts' annual rate and amount of built-up land change}

As shown in Table 2, over the 28-year period of analysis, each of the districts increased in the amount of built-up land within it. The analysis show that the KMA with AUER of $5.03 \%$, recorded one of the highest rates of urban expansion between 1986 and 2001. The AUER of $3.89 \%$ in KMA was however, one of the lowest between 2001 and 2014. In addition, over the entire 28-year, KMA expanded its built-up land at a rate $4.50 \%$ per annum, the lowest rate recorded among all the districts except AsokoreMampong. Despite the diminishing rate of urban expansion relative to the other districts, the KMA in absolute terms, was the most dominant in terms of the distribution of built-up land in the sub-region. It increased its built-up land from $51.8 \mathrm{~km}^{2}(24.4 \%$ of its total land area) in 1986 to $177.5 \mathrm{~km}^{2}$ (83.7\% of its total land area) in 2014. This means that, although the quantum of built-up land increase in the metropolitan core of the sub-region was the biggest over the 28-year period, the rate and intensity of increase, particularly between 2001 and 2014 was relatively slower compared to the remaining seven districts. One possible explanation for the observed trend of urban expansion is that, marking the historical origins of urban growth, the KMA initially attracted a significant share of all development in the sub-region as evidenced by the relatively higher expansion rate between 1986 and 2001. Over time, as most of the land become built-up, and some of the new development occur in previously built-up areas through redevelopment and infilling, lateral expansion would slow down, resulting in the observed falling trend in the rate of built-up land increase during the last 13 years.

The Asokore Mampong municipality, which previously formed part of the administrative area of the KMA, shows a rather interesting trend of urban expansion. Between 1986 and 2001, the district increased the size of its built-up land at a rate of $2.87 \%$, the lowest among all the districts. This is explained by the fact that although it formed part of the KMA during this period, it peripheral location meant that it urbanized at a relatively slower pace compared to the core areas of the metropolis. The larger share of its land would therefore have been undeveloped as one would expect. Between 2001 and 2014 however, the rate of expansion in Asokore Mampong increased to $4.39 \%$. This implies that while urban expansion intensity in the KMA has stagnated over the last 13 years, Asokore Mampong as one of the peripheral districts of the KMA, has been attracting a significant share of new physical development in the sub-region. Indeed, the size of the built-up land of Asokore

Table 2 Amount and rate of built-up land change in GKSR

\begin{tabular}{|c|c|c|c|c|c|c|c|}
\hline \multirow[t]{2}{*}{ District/sub region } & \multirow[t]{2}{*}{ Total area $\left(\mathrm{km}^{2}\right)$} & \multicolumn{3}{|c|}{ Built-up land $\left(\mathrm{km}^{2}\right)$} & \multicolumn{3}{|c|}{ Annual Urban Expansion Rate (\%) } \\
\hline & & 1986 & 2001 & 2014 & 1986-2001 & 2001-2014 & 1986-2014 \\
\hline Atwima Nwabiagya & 596.979 & 6.746 & 9.768 & 41.822 & 2.499 & 11.837 & 6.733 \\
\hline Ejisu-Juaben & 723.216 & 6.611 & 12.423 & 38.192 & 4.295 & 9.023 & 6.464 \\
\hline Kwabre East & 134.822 & 4.289 & 10.154 & 32.752 & 5.913 & 9.426 & 7.530 \\
\hline Atwima Kwanmowa & 290.721 & 3.862 & 9.213 & 30.305 & 5.968 & 9.591 & 7.635 \\
\hline Afigya-Kwabre & 517.277 & 5.411 & 10.172 & 41.701 & 4.298 & 11.464 & 7.566 \\
\hline K.M.A & 212.093 & 51.756 & 108.007 & 177.501 & 5.027 & 3.895 & 4.500 \\
\hline Bosomtwe & 352.575 & 3.392 & 7.728 & 22.436 & 5.642 & 8.544 & 6.980 \\
\hline Asokore Mampong & 22.249 & 5.903 & 9.033 & 15.807 & 2.877 & 4.398 & 3.580 \\
\hline Greater Kumasi Sub-Region & 2849.933 & 87.970 & 176.499 & 400.516 & 4.752 & 6.506 & 5.563 \\
\hline
\end{tabular}


Mampong increased from $5.903 \mathrm{~km}^{2}$ in 1986 $26.5 \%$ of its total land area-to $15.807 \mathrm{~km}^{2}$ in 2014 representing $71.04 \%$ of its total land area. Similar to KMA, Asokore Mampong over the entire 28-year period of analysis with AUER of $3.58 \%$, experienced a relatively slower pace of urban expansion compared to the remaining six districts although. Thus, being originally part of the metropolitan core of the subregion, Asokore Mampong share similar urban expansion characteristics with KMA.

Furthermore, the analysis shows that all the remaining six peripheral districts recorded Average Annual Urban Expansion Rates which were higher than GKSR average of $5.56 \%$. Breaking the results down to the two broad years of analysis, shows a more nuanced trend of urban expansion among these districts. Over the first decade and half, three out of the six peripheral districts namely; Atwima Kwanwoma, Kwabre East and Bosomtwe expanded rapidly than the sub-region at rates of 5.96, 5.9 and $5.64 \%$ respectively. During the same period, Antwima Nwabiagya recorded the lowest rate of expansion at $2.49 \%$. In the last 13 years however, the dynamics changed considerably. Notably, Atwima Nwabiagya-which recorded the lowest expansion rate over the first period-emerged as the as the fastest urbanizing district in the sub-region with annual expansion rate of $11.84 \%$ which was accompanied by a six-fold increase in its built-up land from 6.746 to $41.822 \mathrm{~km}^{2}$. Similarly, Afigya-Kwabre-after expanding at a rate below that of the sub region over the initial 15-year interval-cropped up as the second fastest growing district during the period between 2001 and 2014 with annual expansion rate of $11.46 \%$.

The accelerated rate of urban expansion, particularly over the last 13 years observed among the peripheral districts as compared to the generally slowed pace of expansion in the metropolitan core further supports the finding that urban expansion in recent years has spilled over from the latter into the former.

\section{Districts' share and contribution to built-up land change}

In this section we calculate each district's share of the total built-up land in GKSR (see Fig. 4) and their contribution to the $313 \mathrm{~km}^{2}$ increase in built-up land over the 28-year period (see Fig. 5). The results, depicted in Figs. 4 and 5 are interpreted together as follows.

As shown in Fig. 4, four emergent patterns become apparent with respect to urban expansion trends in the districts. The first describes trends in KMA, the most urbanized area in the sub-region in terms of population size and built-up area. KMA's share of the total builtup land in the sub-region increased from $59 \%$ in 1986 to $61 \%$ in 2001 (see Fig. 4). This represented close to two-thirds $(64 \%)$ of the total built-up land change that occurred in the sub-region over the first 15-year period (see Fig. 5). Between 2001 and 2014, although KMA's built-up land increased in absolute terms by about $70 \mathrm{~km}^{2}$, the metropolis's share of total built-up land change to the sub-region fell to below half (44\%)—see Fig. 4. Over this 13-year period, KMA's contribution to the total built-up land change in the GKSR, diminished substantially to less than a third (31\%) for reasons outlined in the previous section. This notwithstanding, the metropolis being the focal point of historical urban development, maintained its status as the dominant area of urban expansion within the sub-region. In fact, the KMA's share of total built-up land of $177.5 \mathrm{~km}^{2}$ in 2014 was more than four times that of Atwima Nwabiagya's $41.8 \mathrm{~km}^{2}$ which represented the second highest share of total built-up land in the GKSR.

The second pattern shows expansion trends in districts that increased their share of built-up land throughout the years. Three districts namely; Kwabre East, Atwima Kwanwoma and Bosomtwe fell within this group. Kwabre East increased its built-up land share from $4.9 \%$ in 1986 to $5.8 \%$ in 2001 and further to $8.2 \%$ in 2014 (see Fig. 4). Also, the contribution of Kwabre East to the increase in total built-up land in the sub-region increased from $6.04 \%$ during the first 15-year period, to $9.1 \%$ in the last 13-years (see Fig. 5). Similarly, Atwima Kwanwoma appreciated in built-up land share from 4.4 to $5.2 \%$ between 1986 and 2001, and subsequently to $7.6 \%$ in 2014 (see Fig. 4); the district's corresponding contribution to the built-up land increase in the entire sub-region however, decreased marginally from $9.4 \%$ between 1986 and 2001 to $8.5 \%$ between 2001 and 2015 (see Fig. 5). Also, Bosomtwe district recorded an increment in built-up land share from $3.8 \%$ in 1986, the least during the year, to $4.4 \%$ in 2001 and further up $7.6 \%$ thereby moving a step up the ladder in 2014 (see Fig. 4). Bosomtwe's contribution to the built-up land 
Fig. 4 Districts share of total built-up land in GKSR
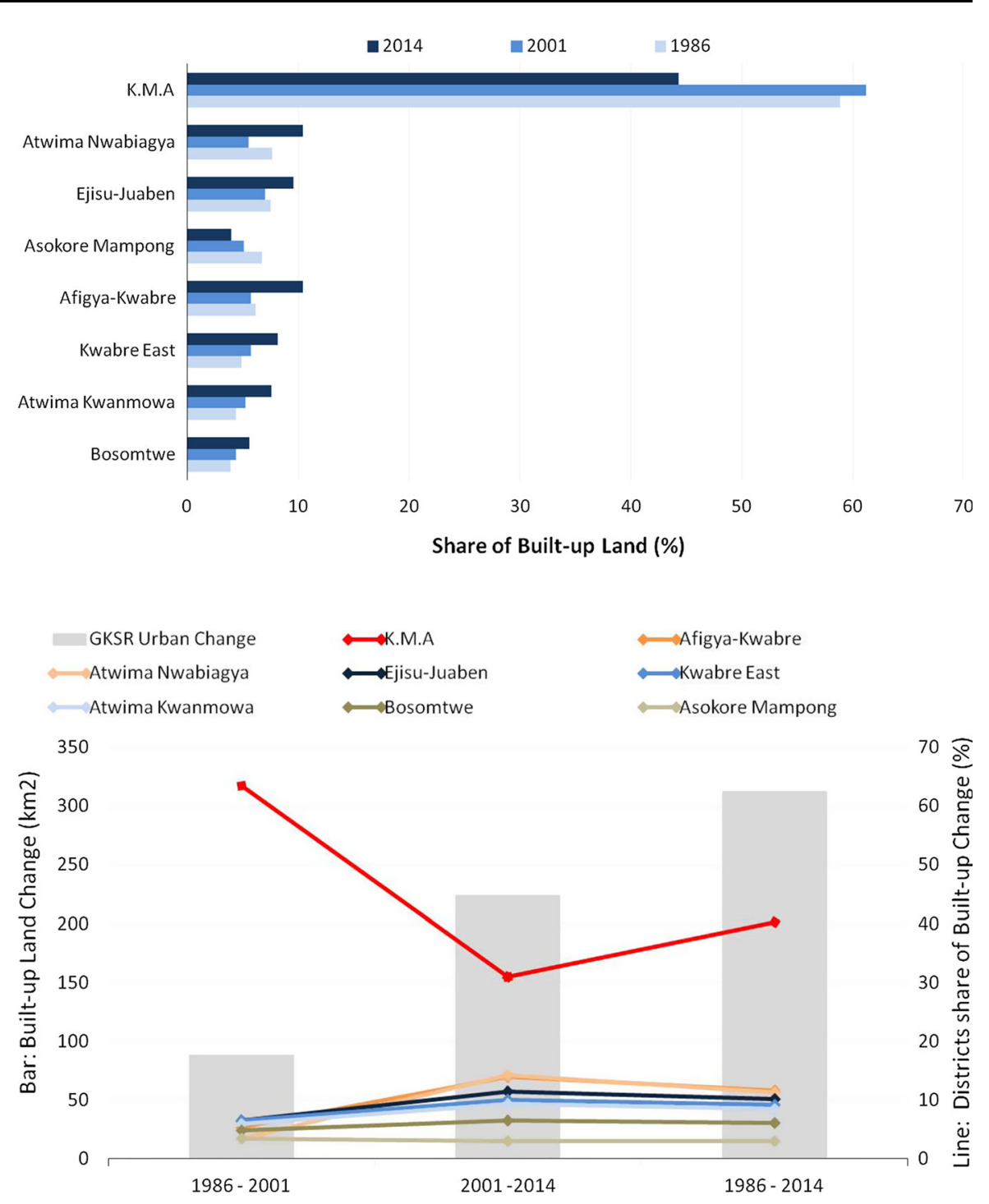

Fig. 5 Districts contribution to built-up land change in GKSR

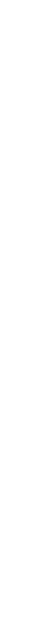

increase in the sub-region also increased from 4.9 to $6.6 \%$ between 1986 and 2001, and 2001 and 2014 respectively (see Fig. 5).

The third group of emergent pattern with respect to share of total built-up land comprises districts that recovered from an initial drop over the first 15-year period to increase in built-up land share during the last 13 years. Three districts namely; Atwima Nwabiagya, Ejisu-Juaben and Efigya Kwabre fall within the group. Having recorded a decline from 7.7 to $5.5 \%$ between 1986 and 2001 which accounted for $3.4 \%$ of the total built-up land increase in the sub-region, Atwima Nwabiagya boosted its built-up land share to $10.4 \%$ in 2014, almost twice that of 2001. Consequently, its contribution to total built-up land change increased to $14.3 \%$ resulting in the district leapfrogging six districts to emerge behind KMA as the second highest contributor to total built-up land increase in the subregion in 2014. Similarly, the Ejisu-Juaben municipality, upon an initial downswing from 7.5 to $7.0 \%$ over the first decade and half, increased its share of built-up land to $9.5 \%$ in 2014. Finally, the Afigya Kwabre appreciated in built-up land share from $5.8 \%$ in 2001 to $10.4 \%$ in 2014 after an earlier dip from $6.2 \%$ in 1986. Consequently, the district sharply increased its contribution to total built-up land increase from 5.4 to $14.1 \%$ between 1986 to 2001 and 2001 to 2014 respectively. 
In contrast, the fourth group comprised districts that diminished in share of built-up land throughout the years. Here, Asokore Mampong which was recently carved out of the KMA is the only candidate district. Using the same district boundary demarcated around 2012 retrospectively, we found that the district's share of built-up land diminished from 6.7 to $5.1 \%$ between 1986 and 2001, and further down to $3.9 \%$ in 2014, the least over the last 13-year period. Despite the consistent declined in share, the district increased in urban land by close to $10 \mathrm{~km}^{2}$ during the 28 -year period. Thus, the fall in share could be attributed to slowed rate of urban expansion relative to other districts in the sub-region.

Overall, during the 28-year period of analysis, KMA experienced the largest amount of built-up land expansion as it accounted for about $40 \%$ of the total built-up land increase recorded in the sub-region. However, over the last 13 years, it contribution to the total built-up land in the sub-region diminished substantially. That of Asokore Mampong, also truncated during both the first 15 years and last 13 years of analysis and accounted for only $3 \%$, the least over the period. Thus, the decline in share of built-up land increase appears a peculiar characteristic of the subregion's core districts. Unlike the first 15 years where no district aside KMA contributed more than a tenth of the total built-up land increase in the sub region, over the latter 13 years, four peripheral districts -Atwima Nwabiagya, Afigya Kwabre, Ejisu Juaben, Kwabre East-each contributed to at least $10 \%$ of the total built-up land increase lending further support to the rapid peri-urbanization underway in the sub-region. This trend is anticipated as urban expansion spreads to the peripheral districts of the sub-region.

\section{Normalized indices for comparative analysis of intensity of urban expansion among districts}

Urban Expansion Intensity Index analysis The Urban Expansion Intensity Index (UEII) normalizes the Annual Urban Expansion Rate of each district by its land area. This allows to compare the expansion intensity of one district to another and of one district to the sub-region as a whole. Over the 28-year period of analysis, KMA consistently experienced the highest intensity of built-up land expansion relative to its size compared to any of the seven remaining districts (see Table 3). In general, three districts-KMA, Asokore
Mampong and Kwabre East with UEII values of 2.117, 1.590 and 0.754 respectively, recorded higher scores in the sub-region. The UEII scores indicate that KMA, increased its built-up land at a high speed. The intensity of expansion in Asokore-Mampong was fast whilst that of Kwabre East was moderate. The EjisuJuaben had the lowest UEII score of 0.156 representing a slow intensity of urban expansion.

Between 1986 and 2001, the intensity of urban expansion was exceptionally high in KMA. Its UEII score of 1.768 , compared to the sub-region's score of 0.207 implies that the rate of built-up land expansion in the KMA, relative to its total land area was more than eight times that of the sub-region as a whole. Asokore Mampong, which was initially part of the core followed with the second highest UEII score of 0.938 , three times as much the third placed Kwabre East's 0.290. Aside these three, the intensity of urban expansion in the other districts were below that of the sub-region with Atwima Nwabiagya recording the lowest UEII score of 0.034 -about six times lower than that of sub-region.

The dynamics of expansion intensity among the districts did not change substantially in terms of order between 2001 and 2014 although it increased in all the districts. The three districts-KMA, Asokore Mampong and Kwabre East with UEII scores of 2.520, 2.342 and 1.289 respectively continued to expand at a much higher intensity than the sub-region as a whole. Unlike the former period, Ejisu-Juaben with UEII of 0.274 recorded the slowest intensity of urban growth during the latter interval whilst Atwima Nwabiagyawhich initially had the lowest UEII moved two places up, although the intensity of expansion occurred at a slow-speed. Indeed, Atwima Nwabiagya multiplied its intensity of expansion by more than twelve times, the highest scale factor over the two periods. This is expected considering that Antwima Nwabiagya recovered from being the slowest expanding district to the fastest by recording the highest Annual Urban Expansion Rate between 2001 and 2014 as pointed earlier. Afigya Kwabre increased its UEII by more than seven times, the second highest scale factor between the two intervals. This is also explained by the rapid annual urban expansion of the district as Afigya Kwabre recorded the second highest AUER during the latter 13-year period. KMA which recorded the lowest AUER between 2001 and 2014 multiplied its UEII by 1.4 between the two sub-periods, the lowest in the sub- 
Table 3 Urban Expansion Intensity Index and Urban Expansion Differentiation Index of districts

\begin{tabular}{|c|c|c|c|c|c|c|}
\hline \multirow[t]{2}{*}{ District/sub-region } & \multicolumn{3}{|c|}{ Urban Expansion Intensity Index } & \multicolumn{3}{|c|}{ Urban Expansion Differentiation Index } \\
\hline & 1986-2001 & 2001-2014 & 1986-2014 & 1986-2001 & 2001-2014 & 1986-2014 \\
\hline Atwima Nwabiagya & 0.034 & 0.413 & 0.210 & 0.445 & 2.585 & 1.463 \\
\hline Ejisu-Juaben & 0.054 & 0.274 & 0.156 & 0.873 & 1.634 & 1.345 \\
\hline Kwabre East & 0.290 & 1.289 & 0.754 & 1.359 & 1.753 & 1.868 \\
\hline Atwima Kwanmowa & 0.123 & 0.558 & 0.325 & 1.377 & 1.804 & 1.927 \\
\hline Afigya-Kwabre & 0.061 & 0.469 & 0.251 & 0.874 & 2.442 & 1.888 \\
\hline K.M.A & 1.768 & 2.520 & 2.117 & 1.080 & 0.507 & 0.684 \\
\hline Bosomtwe & 0.082 & 0.321 & 0.193 & 1.270 & 1.500 & 1.580 \\
\hline Asokore Mampong & 0.938 & 2.342 & 1.590 & 0.527 & 0.591 & 0.472 \\
\hline Greater Kumasi Sub-region & 0.207 & 0.605 & 0.392 & 1 & 1 & 1 \\
\hline
\end{tabular}

region. Thus, AUER reflects the scale factor by which a district's UEII multiplies.

Urban Expansion Differentiation Index (UEDI) analysis Unlike UEII, UEDI identifies urbanization hotpots by normalizing the rate of urban expansion of districts by that of the sub-region thereby improving the comparability of the expansion among the spatial units. This index relates directly to the annual rate of expansion.

The UEDI analysis shows that, over the entire 28-year period, all the districts but for the core onesKMA and Asokore Mampong - urbanized faster than the sub-region, recording UEDI of more than 1. In a descending order, Atwima Kwanwoma (1.927), Afigya-Kwabre (1.888), Kwabre East (1.868), Bosomtwe (1.500) and Atwima Nwabiagya (1.463) emerged as the top five districts in terms of UEDI scores. Thus, in sharp contrast to the UEII which shows that the two districts which make-up the core of the sub-region experienced the largest increase in built-up land, the UEDI analysis goes a step further to indicate the nature and direction of the urban expansion. The analysis shows that in more recent years, the sub-region has been expanding outwardly from the initial core into the peripheral districts. Indeed, over the last 13 years, all the districts except KMA increased their UEDI score.

As explained earlier, there are three broad possible classes of differentiation index namely; fast (i.e. UEDI $>1$ ), moderate (i.e. UEDI $=1$ ) and slow (i.e. UEDI $<1$ ). Based on the values we obtained, the upper class of the UEDI has been categorised further into 'very fast' and 'fast'; similarly, the lower class has been classified further into "slow" and "very slow". Figure 6 shows the five classes of UEDI scores in the sub-region displayed using Jenks Natural Breaks method in ArcGIS. The technique minimizes variance within groups whilst maximizing same between groups.

Figure 6 shows that during the first 15 years, the hotspots of urban expansion in the sub-region included the KMA at the centre, Bosomtwe and Atwima Kwanwoma to the south eastern and south western directions respectively, and Kwabre East to the north eastern direction. The pace of expansion in the eastern (Afigya-Kwabre) and western (Ejisu-Juaben) directions denotes relatively slow speed whilst Asokore Mampong and Atwima Nwabiagya experienced the slowest pace of expansion.

In recent years (i.e. 2001-2014) however, expansion within the sub-region is shifting away from the core districts to the neighbouring peripheral districts in the northern and western directions. The major hotspots of urban expansion, currently are the Atwima Nwabiagya and Afigya-Kwabre districts. These districts are therefore classified as very fast expansion areas. These are followed by Ejisu-Juaben and Bosomtwe districts which have been classified as fast expansion hotspots. Consistent with the AUER and UEII indexes presented in the previous sections, the pace of expansion in Asokore Mampong and KMA, the two core districts of the sub-region, have stalled in recent years making them the slowest spots of urban expansion in the sub-region. 


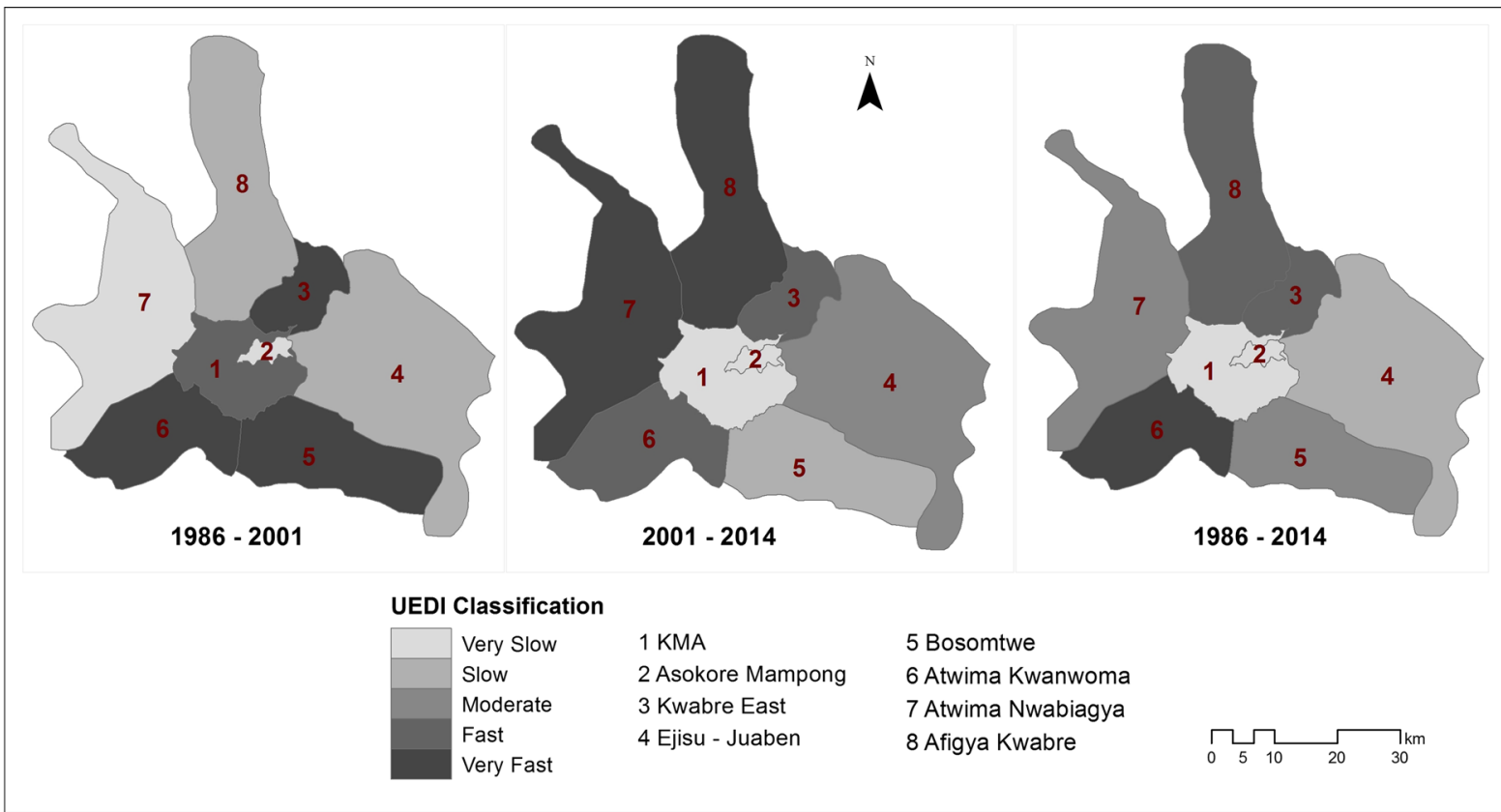

Fig. 6 Urban expansion hotspots in the Greater Kumasi Sub-region for 1986-2001, 2001-2014 and 1986-2014

\section{Discussion}

We set out in this study to examine the spatio-temporal trends of urban expansion in the Greater Kumasi SubRegion in Ghana, West Africa. Using Landsat satellite imagery from 1986, 2001 and 2014 and three complementary metrics, we have quantified the amount, rate and intensity of settlement expansion in the sub-region over a 28-year period.

The analysis shows that over the past 28 years, urban expansion in the GKSR has accelerated at a rate of $5.6 \%$ per annum. Consequently, the sub-region experienced more than four-fold increase in the size of its built-up land from $88 \mathrm{~km}^{2}$ in 1986 to $400 \mathrm{~km}^{2}$ in 2014. We found that a disproportionately larger share (i.e. $72 \%$ ) of the additional $313 \mathrm{~km}^{2}$ of built-up land that accumulated over the 28 -year period, occurred in the last 13 years, at an annual rate of $6.5 \%$. The builtup land change trend is reinforced by the sub-region's expansion intensity index which was found to be relatively slower (i.e. 0.207 ) in the first 15 years but increased to 0.605 in the last 13 years.

The rapid increase in built-up land, particularly over last 13-year, seems to coincide very well with the peak period of unprecedented urbanization in developing countries marked at the beginning of the $21^{\text {st }}$ century. As the analysis has revealed, population growth in the sub-region has been phenomenal over the past three decades. Indeed, population growth and urban expansion in the sub-region have been occurring at similar rates at about 5.1 and $5.6 \%$ per annum respectively. On the average, the population of all the districts in the sub-region is growing at nearly $2 \%$ or higher per annum. In the KMA, the metropolitan core of the sub-region, the current population growth rate of $5.6 \%$, is the highest among all the major cities in Ghana including Accra, the capital, which is currently growing at $4.2 \%$ per annum. With rapid population growth comes the increased demand for land for various activities and the concomitant expansion of existing built-up areas into Greenfield areas. For instance, a study of housing development in the GKSR by Acheampong (2013), found that the total stock of housing in the sub-region quadrupled from 129,864 to 698,042 units at an annual rate of $18 \%$ between 2000 and 2010 alone. Within the KMA alone, the number of houses built increased by more than sixfold over the same period at an annual rate of $23 \%$.

Narrowing the analysis further down to the scale of the districts, we found that pace and intensity of expansion was much more nuanced among the eight administrative districts that constitute the GKSR. In 
terms of the quantum of built-up land, the core districts of the sub-region, comprising KMA and AsokoreMampong-accounted for more than half of the total built-up land increase. Indeed, over the 28-year period of analysis, the KMA recorded the fastest intensity of urban expansion. As the metropolitan core where the CBD of the sub-region is also located, KMA has over the years attracted population and activities which explains its rapid expansion. The dominant role of KMA in terms of the concentration of population and functional land uses in the sub-region is well documented by previous studies (e.g. Kessey and Agyemang 2013; Cobbinah and Amoako 2012).

Our findings points to a general trend where urban expansion has since 2001, stalled in the metropolitan core but accelerated in the peripheral districts. For example, although the KMA recorded one of the highest annual rate of urban expansion (i.e. 5.027 \%), between 1986 and 2001, this decreased to $3.895 \%$ between 2001 and 2014. Moreover, the UEDI analysis revealed that the KMA, which was one of the focal points of expansion between 2001 and 2014 with UEDI of 1.080, ceased to remain the hotspot of urban expansion in the last 13 years recording a UEDI value of 0.507. In addition, Asokore Mampong district, which until 2012, formed part of the administrative area of KMA, also experienced the lowest pace of urban expansion between 1986 and 2001. This however, increased during the last 13 years. The increase in the rate of expansion in Asokore Mampong between 2001 and 2014, coincides with the period when the KMA experienced a decline in the rate of urban expansion. It therefore becomes clear that around this period, Asokore-Mampong, which was located at the periphery of the main built-up land of the KMA, had become one of the receiving ends of the activity spillover from the metropolitan core.

Interpreting the UEII values further indicates that the core districts experienced the fastest intensity of expansion in the last 13 years. However, the AUER analysis shows that the rate of increase of built-up land in these core districts were not necessarily faster than the remaining six peripheral districts. In fact, compared to the remaining six peripheral districts, all of which increased the size of their built-up land at a rate of between 8.5 and $11.84 \%$ per annum between 2001 and 2014, the analysis reveal that the two core districts experienced the lowest rate of expansion during the last 13 years. The UEDI analysis sheds further light on this. It reveals that, although the quantum of built-up land increase in the core districts was significantly higher than each of peripheral districts, the former were not necessarily the hotspots of expansion. The reason for this embedded in the historical growth process of the sub-regional core versus its periphery. Marking the historical origins of urban growth, the KMA in particular, was the focal point of urban development and thus attracted a disproportionately larger share of physical development at the onset of urbanization compared to the other districts. Given that the boundary of the metropolis has remained fixed over the years, the amount of vacant land within it, over time, is expected to progressively diminish whilst land values increase. The higher preference for locations with relatively bigger land size at affordable prices results in peripheral locations becoming more attractive for physical development. Consequently, although the core areas continue to attract development, the additional development is accommodated mainly through the redevelopment of existing uses at higher densities with little lateral expansion. Corollary to this, the rate of physical expansion stalls in these core locations whilst that of the peripheral areas increase faster than was previously experienced.

Moreover, output from all the three metrics computed, reinforces our finding that that the GKSR is currently undergoing rapid peri-urbanization. The analysis show that the highest intensity and fastest rate of urban expansion are currently occurring in northern and north eastern directions. The Atwima Nwabiagya and Afigya Kwabre districts in particular, have become the major hotspots of urban expansion in the sub-region. Previous research (Appiah et al. 2014; Acheampong and Anokye 2013; Amoateng et al. 2013; Owusu-Ansah and O'Connor 2006) support this finding. These studies, conducted mainly in selected peri-urban settlements including Abuakwa, Esereso and Pankrono, point to evidence that a significant proportion of all new urban development over the past decade and half, have occurred within the peri-urban interface of KMA. A number of reasons explain this: First, research points to evidence of redevelopmentinduced displacement of population from the metropolitan core to the urban periphery, resulting from conversion of formerly residential units into commercial uses in the former (see e.g., Adarkwa and Oppong 2006). Other reasons attributed to this pertains to improved transport accessibility and rising 
car ownership in the urban periphery combined with the aggregate cost reducing advantages resulting mainly from the availability of land at relatively cheaper prices at these locations. An initial study by Oduro et al. (2014), for example, established that in 2010 , some $90.5 \%$ of the sub-region's population lived within $4 \mathrm{~km}$ distance of a major road, implying that transport infrastructure development has played a major role in the patterns of physical development.

Clearly, uncontrolled urban expansion at the current rate would have consequences on the environment and livelihoods, in the sub-region. As a result, it is crucial for urban planners and policy makers to have some appreciable knowledge of the likely future urban expansion and its quantifiable environmental and socio-economic impacts. Also, a comprehensive regional growth management strategy would be required to avert unsustainable growth and the attendant negative impacts. Growth management strategies should be tailored to account for the peculiarities of the urban expansion intensity at specific areas in the sub-region. Specifically, densification and intensification strategies should target the metropolitan core of the sub-region. Besides promoting high density development in these core areas, strategies aimed at securing inner-city housing to address the problem of redevelopment-induced displacement of population into the peripheral areas should be pursued.

Within the peri-urban locations where the intensity of urban expansion would most likely accelerate in years to come, growth management strategies should promote guided expansion policies that could accommodate emerging development needs. Where necessary, containment measures could be adopted. For example, the designation and protection of peri-urban farmlands as exclusionary zones where only agricultural-related activities are permitted, could be implemented as a workable alternative to often less effective command-and-control Greenbelt policies. Given that separate local authorities are responsible for each of the districts in the sub-region, effective growth management would depend in part, on effective institutional coordination and strategic partnerships among them.

\section{Conclusion}

In this paper, we have demonstrated that new sources of spatial information such as Landsat satellite images can provide accurate assessment of historical settlement expansion at different spatial scales. Based on these, we have quantified the amount, pace and intensity of urban expansion in the Greater-Kumasi Sub-region over the past 28 years. Our findings not only reveal past trends, but also provide the empirical basis to forecast the sub-region's growth in the future and to manage the urban development process towards sustainable development outcomes. The overall finding of the study points to an on-going process of rapid peri-urbanization in the sub-region. We therefore recommended the need for a comprehensive regional growth management strategy that is grounded in effective strategic partnerships among the respective districts authorities in the sub-region.

Open Access This article is distributed under the terms of the Creative Commons Attribution 4.0 International License (http:// creativecommons.org/licenses/by/4.0/), which permits unrestricted use, distribution, and reproduction in any medium, provided you give appropriate credit to the original author(s) and the source, provide a link to the Creative Commons license, and indicate if changes were made.

\section{References}

Acheampong, R. A. (2013). Situational analysis of housing in the Greater Kumasi Sub-Region, Ghana. Study prepared for the JICA Study Team as Part of the Comprehensive Urban Development Plan for Greater Kumasi Project. doi:10.13140/RG.2.1.3341.1681.

Acheampong, R. A., \& Anokye, P. A. (2013). Understanding households' residential location choice in Kumasi's periurban settlements and the implications for sustainable urban growth. Research on Humanities and Social Sciences, 3(9), 60-70.

Acheampong, R. A., \& Ibrahim, A. (2015). one nation, two planning systems? Spatial planning and multi-level policy integration in Ghana: Mechanisms, challenges and the way forward. Urban Forum. doi:10.1007/s12132-015-9269-1.

Adarkwa, K. K., \& Oppong, R. A. (2006). Gentrification, use conversion and traditional architecture in Kumasi's central business district-case study of Odum Precinct. Journal of Science and Technology (Ghana), 25(2), 80-90.

Alonso, W. (1964). Location and land use. Toward a general theory of land rent. Cambridge, Massachusetts: Harvard University Press.

Amoateng, P., Cobbinah, P. B., \& Owusu-Adade, K. (2013). Managing physical development in peri-urban areas of Kumasi, Ghana: A case of Abuakwa. Journal of Urban and Environmental Engineering (JUEE), 7(1), 96-109.

Angel, S., Sheppard, S., Civco, D. L., Buckley, R., Chabaeva, A., Gitlin, L., et al. (2005). The dynamics of global urban expansion (p. 205). Washington, DC: World Bank, Transport and Urban Development Department. 
Appiah, D. O., Bugri, J. T., Forkuor, E. K., \& Boateng, P. K. (2014). Determinants of peri-urbanization and land use change patterns in peri-urban Ghana. Journal of Sustainable Development, 7(6), 95.

Baloye, D., \& Palamuleni, L. (2015). A comparative land usebased analysis of noise pollution levels in selected urban centers of Nigeria. International Journal of Environmental Research and Public Health, 12(10), 12225.

Burgess, E. W. (1925). The growth of the city: An introduction to a research project. In R. E. Park, E. W. Burgess, \& R. D. McKenzie (Eds.), The city (pp. 47-62). Chicago: The Chicago University Press.

Champion, T. (2001). Urbanization, suburbanization, counterurbanization and reurbanization. In R. Paddison (Ed.), Handbook of urban studies. London: SAGE Publications.

Cobbinah, P. B., \& Amoako, C. (2012). Urban sprawl and the loss of peri-urban land in Kumasi, Ghana. International Journal of Social and Human Sciences, 6(388), e397.

Doan, P., \& Oduro, C. Y. (2012). Patterns of population growth in peri-urban Accra, Ghana. International Journal of Urban and Regional Research, 36(6), 1306-1325.

Duranton, G., \& Puga, D. (2004). Micro-foundations of urban agglomeration economies. In J. V Henderson \& J. E Thisse (Eds.), Handbook of regional and urban economics (Vol. 4, pp. 2063-2117). Elsevier B. V. doi:10.1016/S0169-7218 (04)07048-0.

Eigenbrod, F., Bell, V., Davies, H., Heinemeyer, A., Armsworth, P., \& Gaston, K. (2011). The impact of projected increases in urbanization on ecosystem services. Proceedings of the Royal Society of London B: Biological Sciences, 278(1722), 3201-3208.

Henderson, V. (2002). Urbanization in developing countries. The World Bank research observer, 17(1), 89-112. doi:10. 1093/wbro/17.1.89.

Herold, M., Clarke, K. C., \& Menz, G. (2002, June). A multiscale framework for mapping and analysis of the spatial and temporal pattern of urban growth. In Proceedings of 22nd EARSEL symposium "geoinformation for Europeanwide integration”, Prague.

Hu, Z.-L., Du, P.-J., \& Guo, D.-Z. (2007). Analysis of urban expansion and driving forces in Xuzhou city based on remote sensing. Journal of China University of Mining and Technology, 17(2), 267-271.

Jacobs, J. (1969). The economy of cities. New York: Random House.

Jat, M. K., Garg, P. K., \& Khare, D. (2008). Monitoring and modelling of urban sprawl using remote sensing and GIS techniques. International Journal of Applied Earth Observation and Geoinformation, 10(1), 26-43.

Kessey, K. D., \& Agyemang, F. S. K. (2013). Urbanization and intensive use of space in central business district in a developing city, Ghana: Decongestion programme as city service response; An appraisal. Developing Country Studies, 3(6), 89-96.

Kombe, W. J. (2005). Land use dynamics in peri-urban areas and their implications on the urban growth and form: the case of Dar es Salaam, Tanzania. Habitat International, 29(1), 113-135.

Li, X., Zhang, L., \& Liang, C. (2010). A GIS-based buffer gradient analysis on spatiotemporal dynamics of urban expansion in Shanghai and its major satellite cities.
Procedia Environmental Sciences, 2, 1139-1156. doi:10. 1016/j.proenv.2010.10.123.

Liu, X., Li, X., Chen, Y., Tan, Z., Li, S., \& Ai, B. (2010). A new landscape index for quantifying urban expansion using multi-temporal remotely sensed data. Landscape Ecology, 25(5), 671-682.

Lu, S., Guan, X., He, C., \& Zhang, J. (2014). Spatio-temporal patterns and policy implications of urban land expansion in metropolitan areas: A case study of Wuhan urban agglomeration, Central China. Sustainability, 6(8), 4723-4748.

Masek, J., Lindsay, F., \& Goward, S. (2000). Dynamics of urban growth in the Washington DC metropolitan area, 1973-1996, from Landsat observations. International Journal of Remote Sensing, 21(18), 3473-3486.

McGregor, D. F., Adam-Bradford, A., Thompson, D. A., \& Simon, D. (2011). Resource management and agriculture in the periurban interface of Kumasi, Ghana: Problems and prospects. Singapore Journal of Tropical Geography, 32(3), 382-398.

McGregor, D., \& Simon, D. (Eds.). (2012). The peri-urban interface: Approaches to sustainable natural and human resource use. Abingdon: Routledge.

Oduro, C. Y., Ocloo, K., \& Peprah, C. (2014). Analyzing growth patterns of Greater Kumasi metropolitan area using GIS and multiple regression techniques. Journal of Sustainable Development, 7(5), p13.

Owusu-Ansah, J. K., \& O’Connor, K. (2006). Transportation and physical development around Kumasi, Ghana. World Academy of Science, Engineering and Technology, 17, 129-134.

Pacione, M. (2009). Urban geography: A global perspective. Abingdon: Taylor and Francis.

Potts, D. (2012). Challenging the myths of urban dynamics in sub-Saharan Africa: The evidence from Nigeria. World Development, 40(7), 1382-1393.

Ren, P., Gan, S., Yuan, X., Zong, H., \& Xie, X. (2013). Spatial Expansion and sprawl quantitative analysis of mountain city built-up area. In F. Bian, Y. Xie, X. Cui \& Y. Zeng (Eds.), Geo-informatics in resource management and sustainable ecosystem (pp. 166-176). Berlin: Springer.

Schneider, A. (2012). Monitoring land cover change in urban and peri-urban areas using dense time stacks of Landsat satellite data and a data mining approach. Remote Sensing of Environment, 124, 689-704. doi:10.1016/j.rse.2012.06. 006.

Simon, D., McGregor, D., \& Nsiah-Gyabaah, K. (2004). The changing urban-rural interface of African cities: Definitional issues and an application to Kumasi, Ghana. Environment and Urbanization, 16(2), 235-248.

Sudhira, H. S., Ramachandra, T. V., \& Jagadish, K. S. (2004). Urban sprawl: Metrics, dynamics and modelling using GIS. International Journal of Applied Earth Observation and Geoinformation, 5(1), 29-39.

Torrens, P. M., \& Alberti, M. (2000). Measuring sprawl. London: Centre for Advanced Spatial Analysis-University College London.

Un-habitat. (2010). State of the world's cities 2010/2011: Bridging the urban divide. Abingdon: Earthscan.

Wakode, H. B., Baier, K., Jha, R., \& Azzam, R. (2014). Analysis of urban growth using Landsat TM/ETM data and GIS-A 
case study of Hyderabad, India. Arabian Journal of Geosciences, 7(1), 109-121.

Watson, V. (2009). Seeing from the South: Refocusing urban planning on the globe's central urban issues. Urban Studies, 46(11), 2259-2275.

Webster, D. (2002). On the edge: Shaping the future of periurban East Asia. Stanford: Asia/Pacific Research Center.

Wilson, E. H., Hurd, J. D., Civco, D. L., Prisloe, M. P., \& Arnold, C. (2003). Development of a geospatial model to quantify, describe and map urban growth. Remote Sensing of Environment, 86(3), 275-285.

Xian, G., \& Crane, M. (2005). Assessments of urban growth in the Tampa Bay watershed using remote sensing data. Remote Sensing of Environment, 97(2), 203-215.

Xu, C., Liu, M., Zhang, C., An, S., Yu, W., \& Chen, J. M. (2007). The spatiotemporal dynamics of rapid urban growth in the Nanjing metropolitan region of China. Landscape Ecology, 22(6), 925-937. 